\title{
The Management of Type 2 Diabetic Patients with Hypoglycaemic Agents
}

\author{
Man-Wo Tsang \\ Diabetes Ambulatory Care Centre, Department of Medicine and Geriatrics, United Christian Hospital, 130 Hip Wo Street, \\ Kwun Tong, Hong Kong \\ Correspondence should be addressed to Man-Wo Tsang, tsangman@hkucc.hku.hk
}

Received 11 January 2012; Accepted 15 February 2012

Academic Editors: C. Bizzarri and A. Petryk

Copyright ( 2012 Man-Wo Tsang. This is an open access article distributed under the Creative Commons Attribution License, which permits unrestricted use, distribution, and reproduction in any medium, provided the original work is properly cited.

Type 2 Diabetes Mellitus (T2DM) is characterized by chronic hyperglycemia with disturbance in carbohydrate, lipid, and protein metabolism due to insulin resistance and beta cell dysfunction. Epidemiological studies have confirmed a global pandemic of T2DM, which has created an enormous burden on society, with regard to morbidity, mortality, and health care expenditures. Life style modifications are fundamental not only in early stages of disease management but need to be intensified as disease progresses. United Kingdom Prospective Diabetes Study (UKPDS) has demonstrated the progressive nature of T2DM, and as disease progresses, a combination agents - oral antidiabetic drugs (OAD) and insulin—are needed in order to maintain good sugar control. The general consensus of HbAlc target for most patients is less than 7\%, and various guidelines and algorithms have provided guidance in patient management to keep patient at goal. As our understanding of pathophysiological defects advances, targeting treatment at underlying defects not only enables us to achieve HbAlc goal but also reduces morbidities, mortalities, and progression of the disease. Traditional oral agents like metformin and sulfonylureas have failed to arrest the progression of T2DM. New agents such as TZD, DPP-4 inhibitor, and SGLT-2 may increase our armamentariums against T2DM.

\section{Pathophysiology of T2DM}

Both genetic and environmental factors play an important role in the pathogenesis of T2DM. The best studied pathophysiological defects in T2DM are insulin resistance and insulin secretary dysfunction of $\beta$-cell [1]. The former is primarily represented by decreased insulin-stimulated glucose uptake in skeletal muscle, unsuppressed hepatic glucose production, and increased lipolytic activity in adipose tissue. The latter is an apparent progressive process with both functional defects in islet cell function and, eventually, apparent loss of $\beta$-cell mass [2]. In Pima, Indian insulin resistance proceeds beta cell dysfunction while in others beta-cell dysfunction starts early in the natural history of disease progression [3]. The difference probably related to genetic factors. Recent studies also found that a dysfunction of glucagon secretion and impaired incretin system contribute to hyperglycemia in T2DM, which will provide untapped potential for the betterment of diabetes care [4-6].

\section{Current Oral Antidiabetic Drugs (OADs)}

Currently six classes of OADs are available, and a new one is around the corner. They can be classified into insulin secretagogue (sulfonylureas, meglitinides), insulin sensitizer (thiazolidinediones), decrease glucose flux (alpha-glucosidase inhibitors), incretin mimetic agent (DPP-4 inhibitor), and glycosuric agent (Table 1). An important message from the table is that not a single agent is effective in tackling all the pathophysiological defects of T2DM.

2.1. Sulfonylurea (SU). SUs have played an important role in hyperglycemia management because of their potency, fast action, and relative low cost. The United Kingdom Prospective Diabetes Study (UKPDS) results confirmed that firstline therapy with sulfonylureas in newly diagnosed T2DM is a safe and effective treatment for glucose control [7]. SUs work by stimulating insulin secretion; although there is evidence of extra pancreatic effect, the clinical effect is 
TABLe 1: Different classes of oral antidiabetic agents (OAD) and clinical indications.

\begin{tabular}{|c|c|c|c|c|c|c|c|}
\hline & $\begin{array}{c}\alpha \text { Glucosidase } \\
\text { Inhibitors }\end{array}$ & Meglitinides & SUs & TZDs & Metformin & $\begin{array}{c}\text { DPP-4 } \\
\text { Inhibitors }\end{array}$ & SGLT-2 \\
\hline Insulin deficiency & & $\checkmark$ & $\checkmark$ & & & $\checkmark$ & \\
\hline Insulin resistance & & & & $\checkmark$ & $\checkmark$ & & \\
\hline Excess hepatic glucose output & & & & $\checkmark$ & $\checkmark$ & $\checkmark$ & \\
\hline Intestinal glucose absorption & $\checkmark$ & & & & $\checkmark$ & & \\
\hline Glycosuria & & & & & & & $\checkmark$ \\
\hline
\end{tabular}

Amori et al. [41];

Abdul-Ghani et al. [47];

DeFronzo [17].

probably insignificant [8]. The first-generation agents (acetohexamide, chlorpropamide, tolazamide, and tolbutamide) have a lower binding affinity to the receptor on the $\beta$-cells, so they must be given in higher doses than the second generation agents, (glimepiride, glipizide, gliclazide, and glyburide) which have a higher binding affinity. Among the second generation agents, there are difference in their differential binding specificity to beta-cell SUR1 and SUR-2 in cardiac muscle [9]. All the SUs act by binding to the SUR-1 subunit of KATP channels, causing them to close and increase intracellular potassium, which triggers membrane depolarization. Membrane depolarization opens up calcium channel and causes influx of calcium. Increase in intracellular calcium stimulates migration and exocytosis of insulin granules [10]. Differences in insulin secretory characteristics of the various insulin secretagogues depend on their pharmacokinetic and the affinity and kinetics of their binding to SUR-1 subunit. They have comparable efficacy as illustrated in Table 2. The common side effects are hypoglycemia, weight gain, and secondary failure [11]. Secondarily SU failure rate is reported to be around 5 to 10 percent of patients per year [12]. Secondary failure can have many causes including progression of the disease, stress, infection, introduction of other drugs, for example, corticosteroids, noncompliance, or nonadherence to diet and exercise. Most of the hypoglycemic effects of the sulfonylureas will be observed at one half of the maximum dose recommended for a specific agent [13].

Ever since tolbutamide was implicated with increased mortality secondary to cardiovascular events in the University Group Diabetes Program (UGDP) study, debate on SU cardiovascular safety continues [14]. Recent population studies $[15,16]$ reported increased coronary heart event and mortality with increased dose of SU exposure, and plausible mechanisms have been related to blockage of SUR2 receptor in myocardium and impaired the preischemic precondition of myocardium [17]. While the cardiovascular adverse effects associated with SUs remain controversial, it would be rational to dose SUs at the lowest therapeutically effective dose, thus avoiding the loss of selectivity of these agents for pancreatic KATP channels. Sulfonylureas should be started at low doses and titrated up every 1 to 4 week. A linear dose-response relationship does not exist throughout the manufacturers' dose range for SUs [18]. In patients who are not responding at one half of the maximum dose, an alternative agent or combination therapy should be considered. Combining a drug that increases insulin secretion with one that improves insulin action is therapeutically worthwhile.

\subsection{Nonsulfonylurea Insulin Secretagogue}

2.2.1. Repaglinide/Nateglinide. Nonsulfonylurea insulin secretagogue has a mechanism of action that is similar to SU. They bind to kir-6.2 subunit of SU receptor of $\beta$-cell [10]. Characteristics of these group of agents include a rapid action and short duration of action. The ability to titrate time and dose of the medication to match meal ingestion time greatly decreases in postprandial sugar surge and decreases risk of hypoglycemia. They are good for patients with an irregular meal pattern as they allow greater flexibility for the patient in terms of meal time and dose adjustment. It is to be taken within 30 minutes of each meal with an extra tablet for extra meal and skip a tablet if a meal is skipped. Nonsulfonylurea insulin secretagogues are metabolized by the liver, and although there are no contraindications for patient with renal impairment, the dose should be reduced in cases of impaired liver disease. In general, efficacy is comparable to other SUs with repaganides but less with nateglinides (Tables 2 and 3). Side effects are similar to SUs but less weight gain. Hypoglycemia is uncommon and is usually mild. In the most recent diabetes prevention trial, "The nataglinides and valsartan in impaired glucose tolerance outcome research (navigator) study", Nateglinide have not been proved to have a benefit on any cardiovascular outcome [19].

2.3. Thiazolidinediones. Pioglitazone belongs to the class of thiazolidinediones and is an activator of the nuclear transcription factor, peroxisome proliferator-activated receptor$\gamma$ (PPAR- $\gamma$ ), which modulates the activity of a host of genes that regulate carbohydrate and lipid metabolism. Its major actions are to increase insulin-mediated glucose uptake (improves insulin sensitivity) in muscles, increases adipogenesis, preserves beta cell function, and modulates hepatic gluconeogenesis. The first-generation thiazolidinediones, troglitazone, were withdrawn from the market because of hepatotoxicity and the second-generation, rosiglitazone, is the only in restricted market because of suspected cardiac side-effect. Pioglitazone is the only drug of the class still 
TABLE 2: Mechanism, site of action, and efficacy for oral Antidiabetic agents and CHD benefit.

\begin{tabular}{|c|c|c|c|c|c|}
\hline Drug class & Mechanism of action & $\begin{array}{l}\text { Primary site of } \\
\text { action }\end{array}$ & $\begin{array}{l}\text { Reduction in } \\
\text { FBS }\end{array}$ & $\begin{array}{l}\text { Reduction in } \\
\text { HbAlc }\end{array}$ & CHD benefit \\
\hline Sulfonylureas. . & Insulin release & Pancreas & $3.34-3.88$ & $1.0-2.0$ & - \\
\hline $\begin{array}{l}\text { Nonsulfonylurea } \\
\text { secretagogues }\end{array}$ & Insulin release & Pancreas & $3.34-3.88$ & $0.07-2.0$ & - \\
\hline Biguanides & $\begin{array}{l}\text { Hepatic glucose production; insulin } \\
\text { sensitivity in hepatic and peripheral } \\
\text { tissues }\end{array}$ & $\begin{array}{l}\text { Liver; peripheral } \\
\text { tissues }\end{array}$ & $3.34-3.88$ & $1.0-2.0$ & + \\
\hline Thiazolidinediones & $\begin{array}{l}\text { Insulin sensitivity in peripheral tissues; } \\
\text { hepatic glucose production }\end{array}$ & $\begin{array}{l}\text { Peripheral } \\
\text { tissues; liver }\end{array}$ & $1.90-2.22$ & $0.7-1.0$ & + \\
\hline $\begin{array}{l}\text { Alpha-glucosidase } \\
\text { inhibitors }\end{array}$ & Delay carbohydrate absorption & Small intestines & $1.38-1.66$ & $0.5-1.0$ & + \\
\hline DDPIV inhibitors* & Enhance endogenous GLP-1 & $\begin{array}{l}\beta \text {-cell, stomach, } \\
\text { liver }\end{array}$ & $0.5-1.0$ & $0.73-1.2$ & $+/-$ \\
\hline SGLT-2 $2^{\#}$ & $\begin{array}{l}\text { Inhibitor of renal proximal tubular } \\
\text { reabsorption }\end{array}$ & $\begin{array}{l}\text { Renal tubular } \\
\text { SGLT-2 receptor }\end{array}$ & $0.6-1.2$ & $0.37-0.72$ & $+1-$ \\
\hline
\end{tabular}

DeFronzo [17]; Nathan [66].

\#Bailey et al. [45]. *Amori et al. [41].

widely available. It has moderate efficacy in lowering fasting blood sugar and HbA1c [20]. It has a favorable effect on lipid profile, decreases plasma triglyceride, and increases highdensity lipoprotein [10]. In PRO-ACTIVE study, pioglitazone has shown to reduce composite of all-cause mortality, nonfatal myocardial infarction, and stroke in people with T2DM who have a high risk of macrovascular events [21]. Studies with thiazolidinediones in prediabetes, impaired glucose tolerance (IGT), impaired fasting glucose (IFG), had demonstrated significant reduction in progression from IGT to T2DM by $62-72 \%$ [22-24]. It is more effective in obese subjects and should be used early in the treatment of patients with T2DM to delay disease progression and to minimize the development of complications [25].

Hypoglycemia caused by pioglitazone is usually mild unless in combination with SU and most common sideeffect is fluid retention. Though the incidence of congestive heart failure in pioglitazone treated patients is very low, the risk increases from $1 \%$ to $4-5 \%$ in patients already treated with high dose insulin and pioglitazone [26]. A patient with advance heart failure, New York Heart Association stage III/IV, is a contraindication for pioglitazone. Retrospective analysis of rosiglitazone and pioglitazone data pool revealed that diabetes using thiazolidinediones had a higher risk of distal upper and lower limb fractures compared with those not using thiazolidinediones. Fracture proportions were higher among women and increased with age. The observed excess risk of fractures for women in the pharmaceutical company data set on pioglitazone is 0.8 fractures per 100 patient-years of use [27]. The risk of bladder cancer from recent epidemiological data had prompted France and Germany to suspend pioglitazone in early 2011. In July 2011, the European Medicines Agency's Committee for Medicinal Products for Human Use (CHMP) confirmed that Pioglitazone remains a valid treatment option for certain patients with type 2 diabetes but acknowledges that there is a small increased risk of bladder cancer in patients taking these medicines and warns not to use these medicines in patients with current or a history of bladder cancer or in patients with uninvestigated macroscopic haematuria [28].

2.4. Biguanide (Metformin). The major target of metformin is the enzyme AMP-activated protein kinase (AMP-kinase). Activation of AMP-kinase by metformin results in decrease of hepatic glucose production and increase glucose transport in skeletal muscle [29]. The overall effect is a decrease in hepatic gluconeogenesis due to improvement in hepatic insulin sensitivity. Its insulin sensitizing effect on peripheral tissue has been minimal only. Its efficacy in glucose control had been well documented in UKPDS. Metformin use in the newly diagnosed T2DM achieved comparable HbAlc lowering to SU but without weight gain. Use in obese subgroup in UKPDS was associated with improvement in cardiovascular outcome. The risk of myocardial infarction was reduced by $39 \%$ and the overall diabetes-related mortality by $42 \%$ [30].

Most frequent side-effects are related to the gastrointestinal, tract, namely, nausea, poor appetite, abdominal discomfort, and diarrhoea. Long-term use has also been associated with vitamin B12 deficiency [31,32]. While the most feared lactic acidosis (LA) is actually quite rare and mostly occurred in clinical situations where metformin use is contraindicated, the reported incidence of lactate acidosis in patients with metformin is 3 per 100,000 patient years and a recent Cochrane review suggested there is no evidence that metformin is associated with an increased risk for lactic acidosis when prescribed under the study conditions [33]. The great majority of cases of metformin-associated LA occur in connection with acute illness in diabetic patients where cardiac, hepatic, pulmonary, or renal function is compromised. There are always at least two predisposing factors present in these instances. It is, therefore, reasonable to assume that metformin is just a "bystander" [34].

Metformin is recommended by many algorithm/guidelines as the first-line treatment and can be combined with 


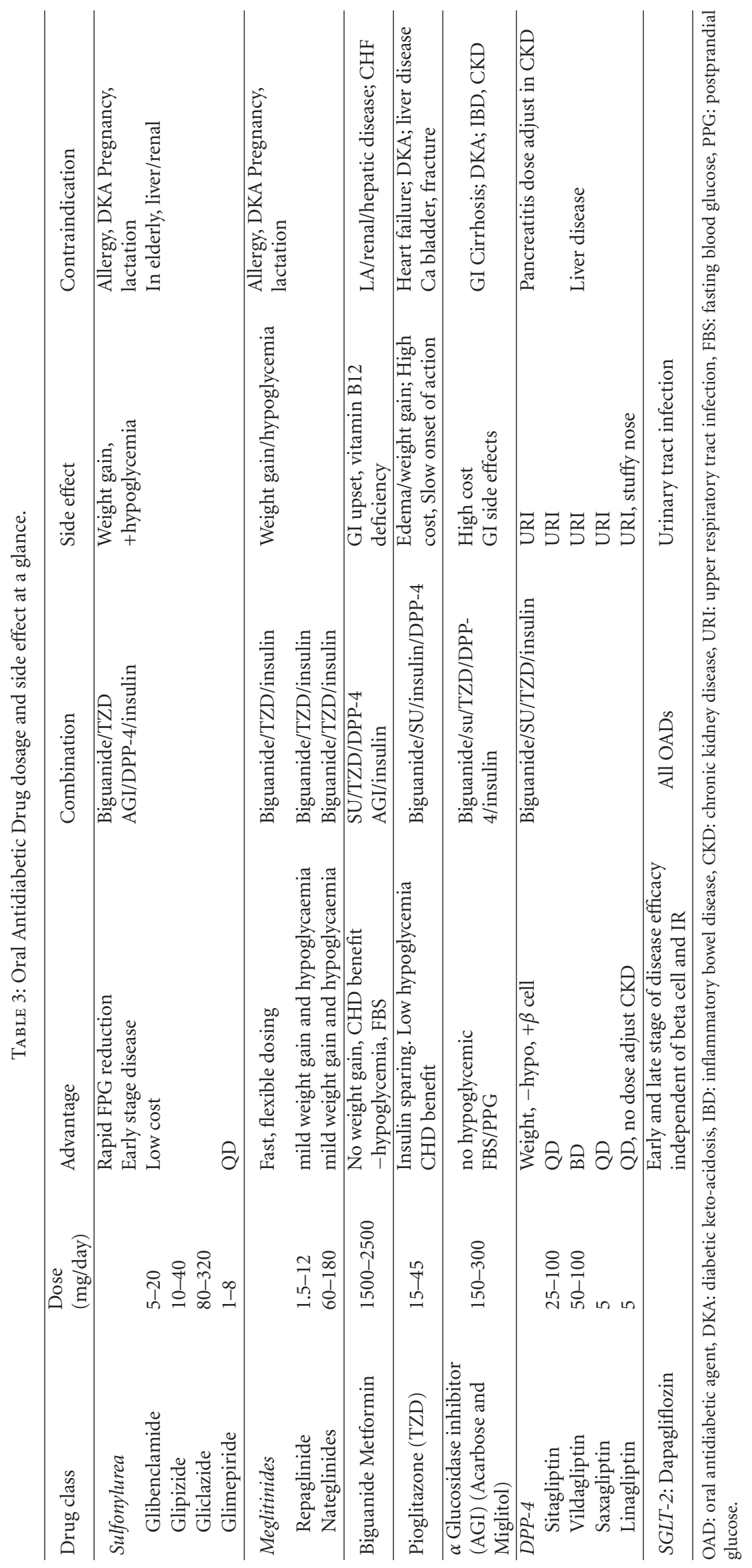


other oral hypoglycaemic agents with complementary action. In order to increase patient's tolerance, it should be started with a low dose and increase gradually over weeks. Maximum dose is $2500 \mathrm{mg}$ per day [35]. It is claimed that sustained preparation is associated with better patient compliance and better HbAlc improvement [36]. The drug should be used with caution in elderly and patients with liver or renal impairment. It is contra-indicated in chronic alcoholism and creatine clearance less than $50 \mathrm{~mL} / \mathrm{min}$. It should be stopped for two days before contrast studies [36].

2.5. $\alpha$-Glucosidase Inhibitor (Miglitol and Acarbose). The mechanisms of all the $\alpha$-glucosidase inhibitors are similar, as a competitive inhibitor to the oligosaccharides for the binding site of $\alpha$-glucosidase. They must be given at the start of each meal. They must be started with a low dose and titrate gradually within weeks. They mainly reduce postprandial hyperglycaemia. The mean reduction in diet control T2DM is about $3.0 \mathrm{mmole} / \mathrm{L}$ and HbAlc $0.9 \%$ [37]. The most frequent side-effects of acarbose treatment are flatulence and diarrhoea. They can be used with T1DM orT2DM. In STOPNIDDM trial, acarbose not only prevented new diabetes mellitus development but also suggested a reduction in hypertension and cardiovascular disease [38].

2.6. Dipeptidyl Peptidase 4 (DPP-4) Inhibitors. People with T2DM are known to have deficient meal-related incretin responses $[4,5]$, resulting in decreased insulin secretion, increased postprandial glucagon levels, and elevated postprandial glucose [39]. This has led to the development of a new class of drug call incretinmimetics, which are GLP1 analogue or GLP-1 receptor agonist and DPP4 inhibitors. The former can only be given by injection while the latter are orally active [40].

The highly selective DPP-4 inhibitors, sitagliptin, saxagliptin, vildagliptin, and linagliptin, prevent normal rapid degradation of endogenous glucagon-like-peptide-1 (GLP-1). They are selective because they inhibit DPP-4 significantly more than the related enzymes, DPP-8, and DPP9. GLP-1 and glucose-dependent insulinotropic polypeptide (GIP) half-lives and protein levels are dramatically increased when DPP-4 inhibitors are administered. These drugs reduce postprandial and fasting glucose concentrations with sustained decrease in HbAlc (0.7-1.3\%) without weight gain or significant hypoglycemia [41]. They potentially preserve $\beta$ cell function with chronic use and have favorable safety profiles. Neither weight loss nor nausea occurs with DPP-4 inhibitors. The most commonly reported adverse events have been mild infections such as nasopharyngitis, upper respiratory tract infection, and headaches. No clinically relevant changes in laboratory immunologic parameters have been found in studies of DPP-4 inhibitors, and pancreatitis was reported at lower rates with the DPP-4 inhibitors compared with other oral antidiabetic agents [42].

2.7. SGLT-2 Inhibitor: Dapagliflozin. A new approach in management of hyperglycemia, as inspired by the congenital familial renal glycosuria [43], is by inhibiting renal glucose reabsorption. SGLT-2 is specific glucose transporter in the proximal renal tubules. SGLT-2 inhibitors, such as dapagliflozin, have been in clinical trials to prove clinical application of these agents [44]. Use of SGLT-2 inhibitor results in glycosuria in the order of $30-80 \mathrm{gm} /$ day, eliminating glucose from the circulation and the equivalent energy. Recent data suggest that it has a moderate HbAlc lowering effect $0.5-0.8 \%$ [45]. Dapagliflozin has demonstrated efficacy, alone or in combination with metformin, in reducing hyperglycemia in people withT2DM $[44,46]$.

It is metabolized by the liver and can be used in patients with renal problem. Their mechanism of action is independent of beta cell or insulin resistance. They can be added to other oral antidiabetic drugs. Potential problems with SGLT2 inhibitor are risk of urinary tract infection and diuretic effect of glycosuria. Additional clinical studies are needed to prove their safety and long-term effect in natural progression of T2DM and cardiovascular complication development [47].

\section{Treatment Target and Guidelines/Algorithm}

In general, $\mathrm{HbAlc}<7 \%$ is the commonly accepted target, but in selected population, HbAlc $<6 \%$ is suggested $[48,49]$. A lower or near normal HbAlc may be a good target for younger patients with a shorter duration of T2DM and those with no history of cardiovascular disease when one hopes to prevent coronary heart disease [50].

Different associations, ADA/EASD, AACE/ACE, NICE, have published different guidelines in diabetes management [51-53]. Most of these adopt a stepwise approach with life style modifications, exercise, and medical nutrition therapy, as the first step, followed by metformin and other oral hypoglycemic agents or insulin in subsequent steps. They differ in the second-line agents recommended, and this has caused confusion among practitioners with different cultural, societal, and economic development.

Instead of a conventional stepwise approach, the DeFronzo algorithm recommends metformin, pioglitazone, and exenatide (GLP-1 agonist) as initial comprehensive treatment [54]. The triple therapy will work complementary to each other with the advantage of low risk of hypoglycemia, no weight gain, and potential coronary heart disease risk protection, and prevention of beta cell function deterioration. Definite proof of the therapy will come after completion of the study, which is funded by ADA recently.

\section{Strategy}

A uniform treatment protocol is impossible for all regions and no one protocol fits all patients. After life style modifications, pharmaceutical treatment usually starts with monotherapy, unless the patient is very symptomatic. If adequate blood glucose control is not attained using a single oral agent after 3-6 months, a combination of agents with different mechanisms of action may have additive therapeutic effects and result in better glucose control. Further deterioration is to be expected with time, and insulin in various combinations will be required ultimately if tight control of blood 
Life style modification $\longrightarrow$ Life style modification $\longrightarrow$ Life style modification

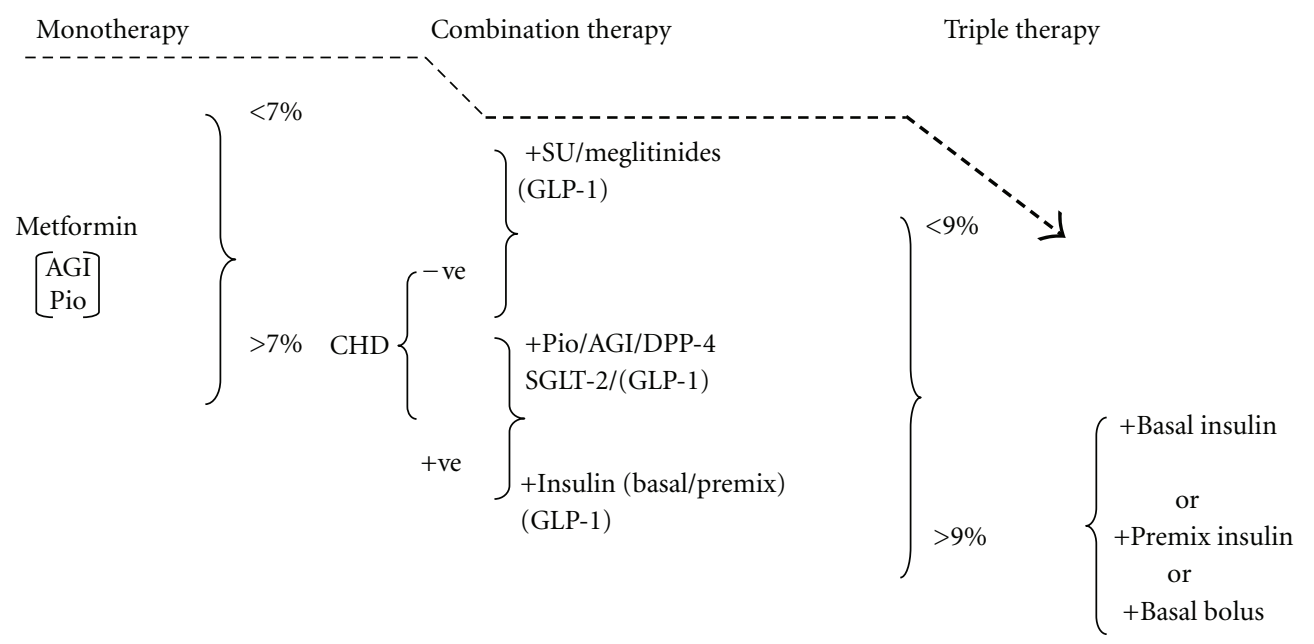

AGI: alpha glucosidase inhibitor, Pio: pioglitazone,

SU: sulfonylurea; DPP-4: dipeptidyl peptidase 4 (DPP-4) inhibitors

GLP-1: glucagon-like-peptide-1

Figure 1: Algorithm in management of T2DM. NICE guidelines, May issue 2009 [53], Nathan et al. [51], Rodbard et al. [49], and Inzucchi and McGuire [65].

sugar is required. Potential combinations are illustrated in Figure 1. In practice, management of people with T2DM will depend on consideration of at least four different factors; patient, disease, drug, and physician as depicted in Figure 2.

4.1. Disease. Treatment strategy is to address the pathophysiological defects and aims at correcting one or more of these physiologic abnormalities, that is, insulin resistance, beta-cell dysfunction, and increased hepatic glucose output, and not simply on the reduction in HbAlc. This will imply use of different drugs or combination of drugs at different stages of the disease. Treatment must be started early in the natural history of T2DM if $\beta$-cell failure is to be prevented because of the "Metabolic legacy" as demonstrated by UKPDS $[1,55]$.

4.2. Drug: Potency and Safety the New and Old Agents. Metformin and SU have served us well over half century and they are still recommended by various algorithms. However, they failed to sustain glucose control as a result of $\beta$-cell failure as demonstrated by UKPDS [56]. Hypoglycemia is a major and potential lethal side effect with SUs, especially in elderly and patient with cardiovascular disease (CHD). This can be minimized by dosing at less than the manufacturers' maximal recommended dose and avoiding high risk patients and agent [14-18]. New agents such as pioglitazone and DPP-4 inhibitors may offer less hypoglycemia, potential $\beta$-cell protection, sustain glycaemic control, and possibly $\mathrm{CHD}$ protection in high risk patients. But pioglitazone is associated with significant distal fracture, heart failure, and potential risk of bladder cancer. Though initial clinical data

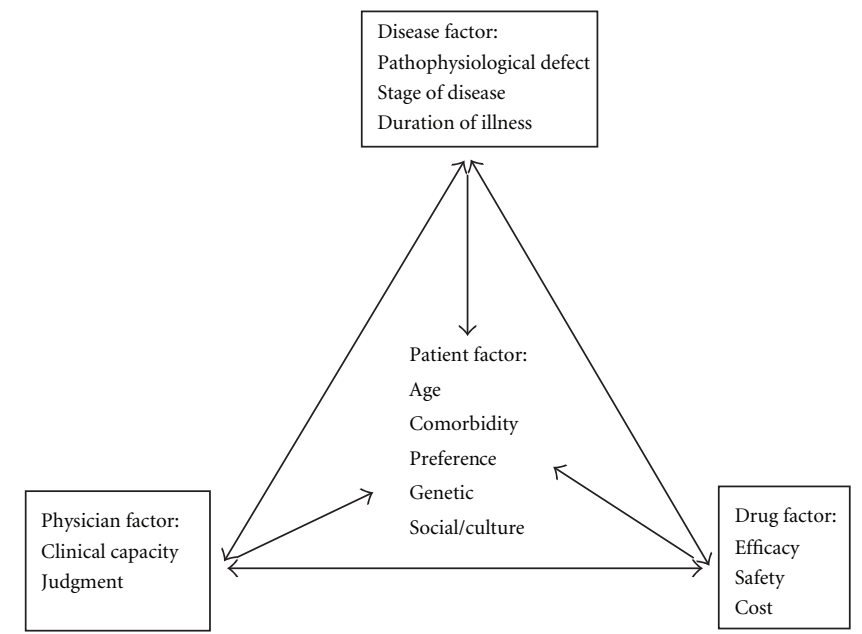

FIGURE 2: Interaction between different factors in choosing an appropriate agent for T2DM management.

are promising, there are still no long-term safety data about incretin-based treatment.

4.3. Patient. Different patients may need different regimens. Genetic and cultural background difference may affect their response and adherence to specific drugs. The comorbid states, such as coronary heart disease and kidney disease, may pose them at particular risk such as heart failure, lactate acidosis, hypoglycemia, and even fatal myocardial events. As we learnt from ACCORD and ADVANCE studies that 
patients with long duration disease or established coronary disease should not have aggressive lowering of blood sugar $[57,58]$.

4.4. Physician. Despite management guidelines recommending increasingly tight targets for glycaemia control, a significant proportion of patients with type 2 diabetes do not achieve target levels of glycaemia control. A number of studies have shown that when targets are lower, a smaller proportion of patients reach target; in China (CODIC-2), $68 \%$ had HbAlc < 7.5\% [59], Canada, 51\% had HbAlc $\leq 7 \%$ [60], and USA, only $37 \% \mathrm{HbAlc}$ had $<7 \%$ [61]. Europe had 31\% HbAlc $<6.5 \%$ [62]. In a cross-sectional survey of 24317 patients with diabetes mellitus among five different Asia countries, the majority (55\%) had values exceeding $8 \%$, indicative of poor glycogenic control [63]. There appeared still a gap between what is known and what is being done. Study also found that because of clinical inertia, patients accumulate several years of hyperglycemia before therapy is intensified or changed. Encourage to change to an alternative agent or early combination therapy when most of the hypoglycemic effects are not observed at one half the maximum dose of the sulfonylureas should be the first step to reduce time of exposure to chronic hyperglycemia and possible complication $[13,64]$. The decision to use specific agent depends on judgment of physician after balancing all the above factors.

\section{Conclusion}

Conventionally, drug interventions for T2DM have focused on improvements of $\mathrm{HbAlc}$, which proved to be important in prevention of microvascular complication and cardiovascular benefit in long term. However, their efficacy tends to fail as disease progresses. New agents targeting at insulin resistance and $\beta$-cell protection offer effective regimens to slow disease progression and complication development. Algorithm and guidelines may offer suggestions in choosing appropriate agents for general patient only. Each patient differs with his particulars and how to choose the appropriate agent depends on each practitioner's clinical judgment after taking into consideration the risks and benefits of each agent and unique clinical features of each patient and stages of the disease. Data are gathering to enable us to consider agent or combination of agents to help arrest progression of T2DM and prevent complication.

\section{Conflict of Interests}

The author has no Conflict of Interests.

\section{References}

[1] C. Weyer, C. Bogardus, D. M. Mott, and R. E. Pratley, "The natural history of insulin secretory dysfunction and insulin resistance in the pathogenesis of type 2 diabetes mellitus," Journal of Clinical Investigation, vol. 104, no. 6, pp. 787-794, 1999.

[2] S. E. Kahn, "The relative contributions of insulin resistance and beta-cell dysfunction to the pathophysiology of Type 2 diabetes," Diabetologia, vol. 46, no. 1, pp. 3-19, 2003.
[3] D. LeRoith, " $\beta$-cell dysfunction and insulin resistance in type 2 diabetes: role of metabolic and genetic abnormalities," American Journal of Medicine, vol. 113, no. 6, pp. 3S-11S, 2002.

[4] M. Nauck, F. Stockmann, R. Ebert, and W. Creutzfeldt, "Reduced incretin effect in Type 2 (non-insulin-dependent) diabetes," Diabetologia, vol. 29, no. 1, pp. 46-52, 1986.

[5] D. J. Drucker and M. A. Nauck, "The incretin system: glucagon-like peptide-1 receptor agonists and dipeptidyl peptidase-4 inhibitors in type 2 diabetes," The Lancet, vol. 368, no. 9548, pp. 1696-1705, 2006.

[6] A. Mitrakou, D. Kelley, M. Mokan et al., "Role of reduced suppression of glucose production and diminished early insulin release in impaired glucose tolerance," The New England Journal of Medicine, vol. 326, no. 1, pp. 22-29, 1992.

[7] R. R. Holman, "Long-term efficacy of sulfonylureas: a United Kingdom Prospective Diabetes Study perspective," Metabolism, vol. 55, no. 1, pp. S2-S5, 2006.

[8] Extrapancreatic Effect of Sulfonylurea. International Text Book of Diabetes, John Wiley \& Sons, Chichester, UK, 2nd edition, 19.

[9] H. E. Lebovitz, "Oral hypoglycaemic agents for T2DM," in Joslin Diabetes Mellitus, R. C. Kahn, G. C. Weir, G. L. King, A.M. Jacobson, and A.C. Moses, Eds., chapter 41, p. 693, Lippincott Williams \& Wilkins, 14th edition, 2004.

[10] J. E. Gerich, "Oral hypoglycemic agents," The New England Journal of Medicine, vol. 321, no. 18, pp. 1231-1245, 1989.

[11] L. Jackson and L. Robertson, "Sulphonylureas (specifically glibenclamide) and their correct dosage," South African Medical Journal, vol. 76, no. 6, pp. 286-289, 1989.

[12] S. Stenman, A. Melander, P.-H. Groop et al., "What is the benefit of increasing the sulfonylurea dose?" Annals of Internal Medicine, vol. 118, pp. 169-172, 1993.

[13] C. L. Meinert, G. L. Knatterud, T. E. Prout, and C. R. Klimt, "A study of the effects of hypoglycemic agents on vascular complications in patients with adult-onset diabetes. II. Mortality results," Diabetes, vol. 19, pp. 789-830, 1970.

[14] M. Miller and G. L. Knatterud, "A study of the effects of hypoglycemic agents on vascular complications in patients with adult onset diabetes. VI. Supplementary report on nonfatal events in patients treated with tolbutamide," Diabetes, vol. 25, no. 12, pp. 1129-1153, 1976.

[15] S. H. Simpson, S. R. Majumdar, R. T. Tsuyuki, D. T. Eurich, and J. A. Johnson, "Dose-response relation between sulfonylurea drugs and mortality in type 2 diabetes mellitus: a population-based cohort study," Canadian Medical Association Journal, vol. 174, no. 2, pp. 169-174, 2006.

[16] T. K. Schramm, G. H. Gislason, A. Vaag et al., "Mortality and cardiovascular risk associated with different insulin secretagogues compared with metformin in type 2 diabetes, with or without a previous myocardial infarction: a nationwide study," European Heart Journal, vol. 32, no. 15, pp. 1900-1908, 2011.

[17] R. A. DeFronzo, "Pharmacologic therapy for type 2 diabetes mellitus," Annals of Internal Medicine, vol. 131, no. 4, pp. 281303, 1999.

[18] V. Rambiritch, P. Naidoo, and N. Butkow, "Dose-response relationships of sulfonylureas: will doubling the dose double the response?" Southern Medical Journal, vol. 100, no. 11, pp. 1132-1136, 2007.

[19] R. R. Holman, S. M. Haffner, J. J. McMurray et al., "Effect of nateglinide on the incidence of diabetes and cardiovascular events," The New England Journal of Medicine, vol. 362, no. 16, pp. 1463-1476, 2010.

[20] S. Mudaliar and R. R. Henry, "New oral therapies for type 2 diabetes mellitus: the glitazones or insulin sensitizers," Annual Review of Medicine, vol. 52, pp. 239-257, 2001. 
[21] J. A. Dormandy, B. Charbonnel, D. J. Eckland et al., "Secondary prevention of macrovascular events in patients with type 2 diabetes in the PROactive Study (PROspective pioglitAzone Clinical Trial in macroVascular Events): a randomised controlled trial," The Lancet, vol. 366, no. 9493, pp. 1279-1289, 2005.

[22] A. H. Xiang, R. K. Peters, S. L. Kjos et al., "Effect of pioglitazone on pancreatic $\beta$-cell function and diabetes risk in Hispanic women with prior gestational diabetes," Diabetes, vol. 55, no. 2, pp. 517-522, 2006.

[23] R. A. DeFronzo, D. Tripathy, D. C. Schwenke et al., "Pioglitazone for diabetes prevention in impaired glucose tolerance," The New England Journal of Medicine, vol. 364, pp. 1104-1115, 2011.

[24] S. E. Kahn, S. M. Haffner, M. A. Heise et al., "Glycemic durability of rosiglitazone, metformin, or glyburide monotherapy," The New England Journal of Medicine, vol. 355, no. 23, pp. 2427-2443, 2006.

[25] D. M. Kendall, "Thiazolidinediones: the case for early use," Diabetes Care, vol. 29, no. 1, pp. 154-157, 2006.

[26] R. W. Nesto, D. Bell, R. O. Bonow et al., "Thiazolidinedione use, fluid retention, and congestive heart failure: a consensus statement from the American Heart Association and American Diabetes Association," Circulation, vol. 108, no. 23, pp. 2941-2948, 2003.

[27] http://www.ukmicentral.nhs.uk/headline/database/story.asp? NewsID=5956.

[28] http://www.ema.europa.eu/docs/en_GB/document_library/ Press_release/2011/07/WC500109176.pdf.

[29] G. Zhou, R. Myers, Y. Li et al., "Role of AMP-activated protein kinase in mechanism of metformin action," Journal of Clinical Investigation, vol. 108, no. 8, pp. 1167-1174, 2001.

[30] R. Turner, "Effect of intensive blood-glucose control with metformin on complications in overweight patients with type 2 diabetes (UKPDS 34)," The Lancet, vol. 352, no. 9131, pp. 854865, 1998.

[31] R. Z. W. Ting, C. C. Szeto, M. H. M. Chan, K. K. Ma, and K. M. Chow, "Risk factors of vitamin B12 deficiency in patients receiving metformin," Archives of Internal Medicine, vol. 166, no. 18, pp. 1975-1979, 2006.

[32] G. I. Varughese, A. A. Tahrani, and J. H. B. Scarpello, “The long and short of metformin-related vitamin B12 deficiency [3]," Archives of Internal Medicine, vol. 167, no. 7, pp. 729-730, 2007.

[33] S. R. Salpeter, E. Greyber, G. A. Pasternak, and E. E. Salpeter Posthumous, "Risk of fatal and nonfatal lactic acidosis with metformin use in type 2 diabetes mellitus," Cochrane Database of Systematic Reviews, no. 1, Article ID CD002967, 2010.

[34] J. G. Heaf and W. van Biesen, "Metformin and chronic renal impairment: a story of choices and ugly ducklings," Clinical Diabetes, vol. 29, no. 3, pp. 97-101, 2011.

[35] A. J. Garber et al., "Maximum dose and GI side effect," The American Journal of Medicine, vol. 102, p. 491, 1997.

[36] L. A. Donnelly, A. D. Morris, and E. R. Pearson, "Adherence in patients transferred from immediate release metformin to a sustained release formulation: a population-based study," Diabetes, Obesity and Metabolism, vol. 11, no. 4, pp. 338-342, 2009.

[37] S. K. Morcos and H. S. Thomsen, "European Society of Urogenital Radiology guidelines on administering contrast media," Abdominal Imaging, vol. 28, no. 2, pp. 187-190, 2003.
[38] J.-L. Chiasson, R. G Josse, R. Gomis et al., "Acarbose for prevention of type 2 diabetes mellitus: the STOP-NIDDM randomized trial," The Journal of the American Medical Association, vol. 4, no. 486, pp. 494-2003.

[39] C. F. Deacon, "Incretin-based treatment of type 2 diabetes: glucagon-like peptide-1 receptor agonists and dipeptidyl peptidase-4 inhibitors," Diabetes, Obesity and Metabolism, vol. 9, no. 1, pp. 23-31, 2007.

[40] D. Hinnen, L. L. Nielsen, A. Waninger, and P. Kushner, "Incretin mimetics and DPP-IV inhibitors: new paradigms for the treatment of type 2 diabetes," Journal of the American Board of Family Medicine, vol. 19, no. 6, pp. 612-620, 2006.

[41] R. E. Amori, J. Lau, and A. G. Pittas, "Efficacy and safety of incretin therapy in type 2 diabetes: systematic review and metaanalysis," Journal of the American Medical Association, vol. 298, no. 2, pp. 194-206, 2007.

[42] K. R. Richard, J. S. Shelburne, and J. K. Kirk, "Tolerability of dipeptidyl peptidase-4 inhibitors: a review," Clinical Therapeutics, vol. 33, no. 11, pp. 1609-1629, 2011.

[43] L. J. Elsas and L. E. Rosenberg, "Familial renal glycosuria: a genetic reappraisal of hexose transport by kidney and intestine," Journal of Clinical Investigation, vol. 48, no. 10, pp. 18451854, 1969.

[44] B. Komoroski, N. Vachharajani, Y. Feng, L. Li, D. Kornhauser, and M. Pfister, "Dapagliflozin, a novel, selective SGLT2 inhibitor, improved glycemic control over 2 weeks in patients with type 2 diabetes mellitus," Clinical Pharmacology and Therapeutics, vol. 85, no. 5, pp. 513-519, 2009.

[45] C. J. Bailey, J. L Gross, L. Bastone et al., "SGLT2 inhibitors: glucuretic treatment for type 2 diabetes: the renal glucostat," The Lancet, vol. 375, pp. 2223-2233, 2010.

[46] J. F. List, V. Woo, E. Morales, W. Tang, and F. T. Fiedorek, "Sodium-glucose cotransport inhibition with dapagliflozin in type 2 diabetes," Diabetes Care, vol. 32, no. 4, pp. 650-657, 2009.

[47] M. A. Abdul-Ghani, L. Norton, and R. A. DeFronzo, "Role of sodium-glucose cotransporter 2 (SGLT 2) inhibitors in the treatment of type 2 diabetes," Endocrine Reviews, vol. 32, no. 4, pp. 515-531, 2011.

[48] American Diabetes Association, "Standards of medical care in diabetes-2010," Diabetes Care, vol. 33, supplement 1, no. 2, pp. S11-S61, 2010.

[49] H. W. Rodbard, P. S. Jellinger, J. A. Davidson et al., "Statement by an American Association of Clinical Endocrinologists/American College of Endocrinology Consensus Panel on type 2 diabetes mellitus: an algorithm for glycemic control," Endocrine Practice, vol. 15, no. 6, pp. 540-559, 2009.

[50] J. S. Skyler, R. Bergenstal, R. O. Bonow et al., "Intensive glycemic control and the prevention of cardiovascular events: implications of the ACCORD, ADVANCE, and VA diabetes trials: a position statement of the American Diabetes Association and a scientific statement of the American College of Cardiology Foundation and the American Heart Association," Diabetes Care, vol. 32, pp. 187-192, 2009.

[51] D. M. Nathan, J. B. Buse, M. B. Davidson et al., "Medical management of hyperglycemia in type 2 diabetes: a consensus algorithm for the initiation and adjustment of therapy," Diabetes Care, vol. 32, no. 1, pp. 193-203, 2009.

[52] H. W. Rodbard, L. Blonde, S. S. Braithwaite et al., "American Association of Clinical Endocrinologists medical guidelines for clinical practice for the management of diabetes mellitus," Endocrine Practice, vol. 13, supplement 1, pp. 1-68, 2007. 
[53] Nation Institution of Health and Clinical Excellence, "Type 2 diabetes: newer agents for blood glucose control in type 2 diabetes," 2009.

[54] R. B. Aguilar, "Evaluating treatment algorithms for the management of patients with type 2 diabetes mellitus: a perspective on the definition of treatment success," Clinical Therapeutics, vol. 33, no. 4, pp. 408-424, 2011.

[55] J. Chalmers and M. E. Cooper, "UKPDS and the legacy effect," The New England Journal of Medicine, vol. 359, no. 15, pp. 1618-1620, 2008.

[56] R. C. Turner, C. A. Cull, V. Frighi, and R. R. Holman, "Glycemic control with diet, sulfonylurea, metformin, or insulin in patients with type 2 diabetes mellitus. Progressive requirement for multiple therapies (UKPDS 49)," Journal of the American Medical Association, vol. 281, no. 21, pp. 2005-2012, 1999.

[57] The Action to Control Cardiovascular Risk in Diabetes Study Group, "Effects of intensive glucose lowering in type 2 diabete," The New England Journal of Medicine, vol. 358, pp. 25452559, 2008.

[58] The ADVANCE Collaborative Group, "Intensive blood glucose control and vascular outcomes in patients with type 2 diabetes," The New England Journal of Medicine, vol. 358, pp. 2560-2572, 2008.

[59] C. Xingbao, "Chinese Health Economics 2003; Ling T.," China Diabetic Journal, 2003.

[60] S. B. Harris, J.-M. Ekoé, Y. Zdanowicz, and S. WebsterBogaert, "Glycemic control and morbidity in the Canadian primary care setting (results of the diabetes in Canada evaluation study)," Diabetes Research and Clinical Practice, vol. 70, no. 1, pp. 90-97, 2005.

[61] S. H. Saydah, J. Fradkin, and C. C. Cowie, "Poor control of risk factors for vascular disease among adults with previously diagnosed diabetes," Journal of the American Medical Association, vol. 291, no. 3, pp. 335-342, 2004.

[62] A. Liebl, M. Mata, and E. Eschwège, "Evaluation of risk factors for development of complications in Type II diabetes in Europe," Diabetologia, vol. 45, no. 6, pp. S23-S28, 2002.

[63] L.-M. Chuang, S. T. Tsai, B. Y. Huang, and T. Y. Tai, “The status of diabetes control in Asia-a cross-sectional survey of 24317 patients with diabetes mellitus in 1998," Diabetic Medicine, vol. 19, no. 12, pp. 978-985, 2002.

[64] C. E. Koro, S. J. Bowlin, N. Bourgeois, and D. O. Fedder, "Glycemic control from 1988 to 2000 among U.S. adults diagnosed with type 2 diabetes: a preliminary report," Diabetes Care, vol. 27, no. 1, pp. 17-20, 2004.

[65] S. E. Inzucchi and D. K. McGuire, "New drugs for the treatment of diabetes part II: incretin-based therapy and beyond," Circulation, vol. 117, no. 4, pp. 574-584, 2008.

[66] D. M. Nathan, "Initial management of glycemia in type 2 diabetes mellitus," The New England Journal of Medicine, vol. 347, pp. 1342-1349, 2002. 


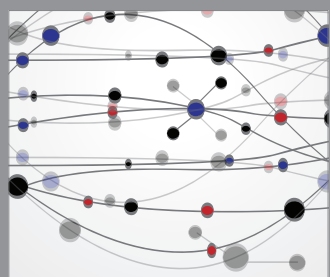

The Scientific World Journal
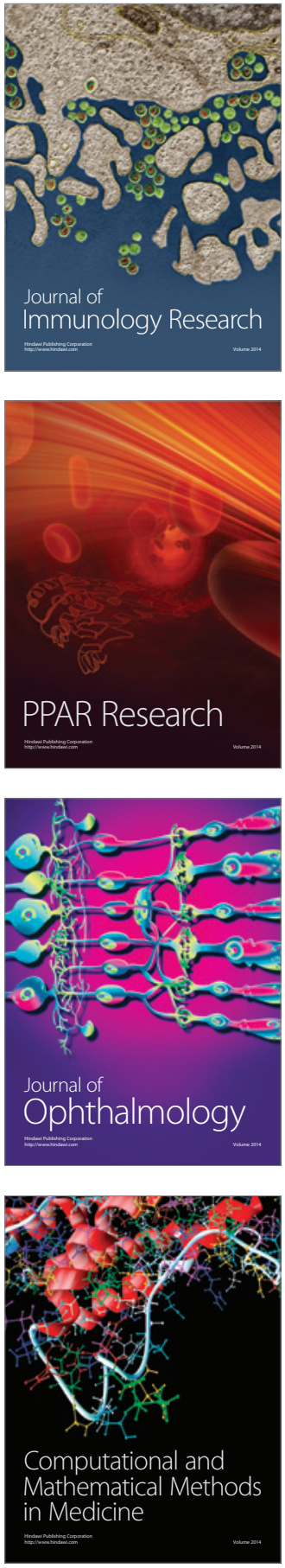

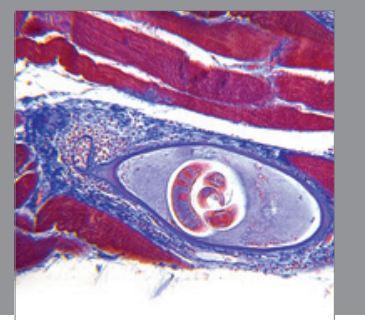

Gastroenterology

Research and Practice
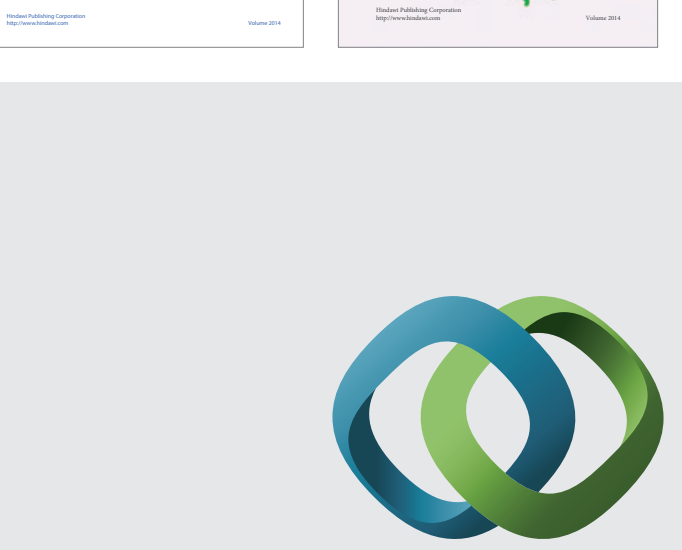

\section{Hindawi}

Submit your manuscripts at

http://www.hindawi.com
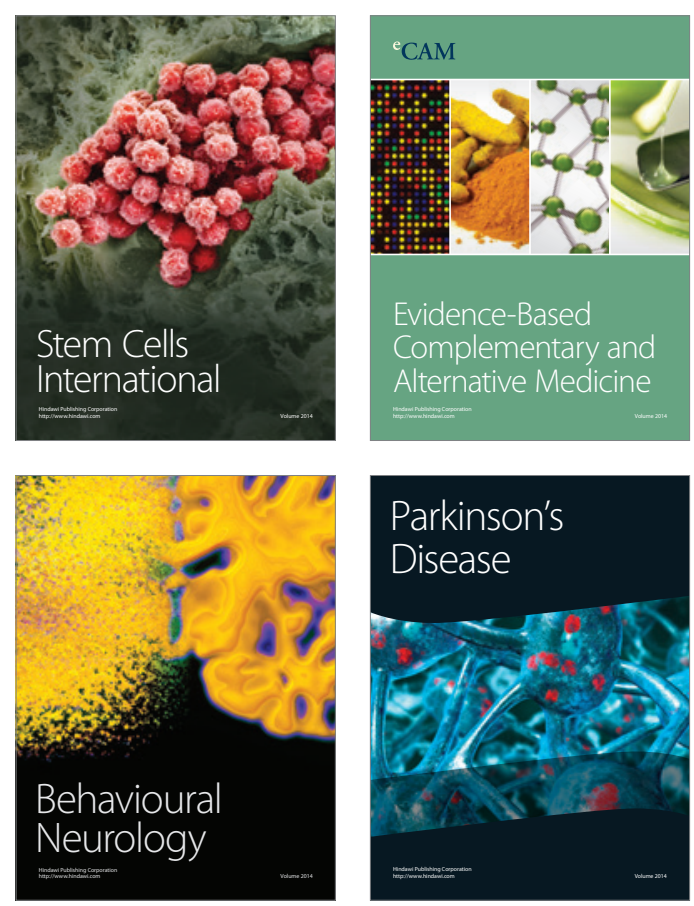

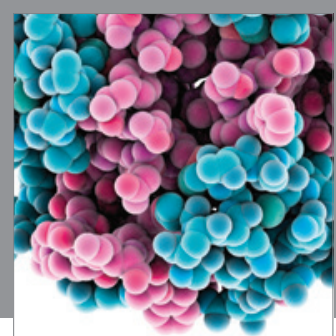

Journal of
Diabetes Research

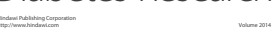

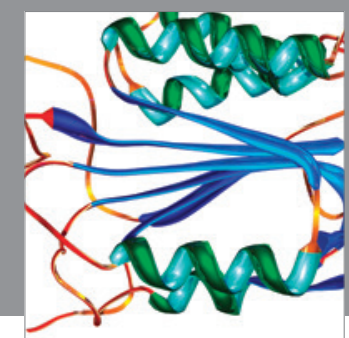

Disease Markers
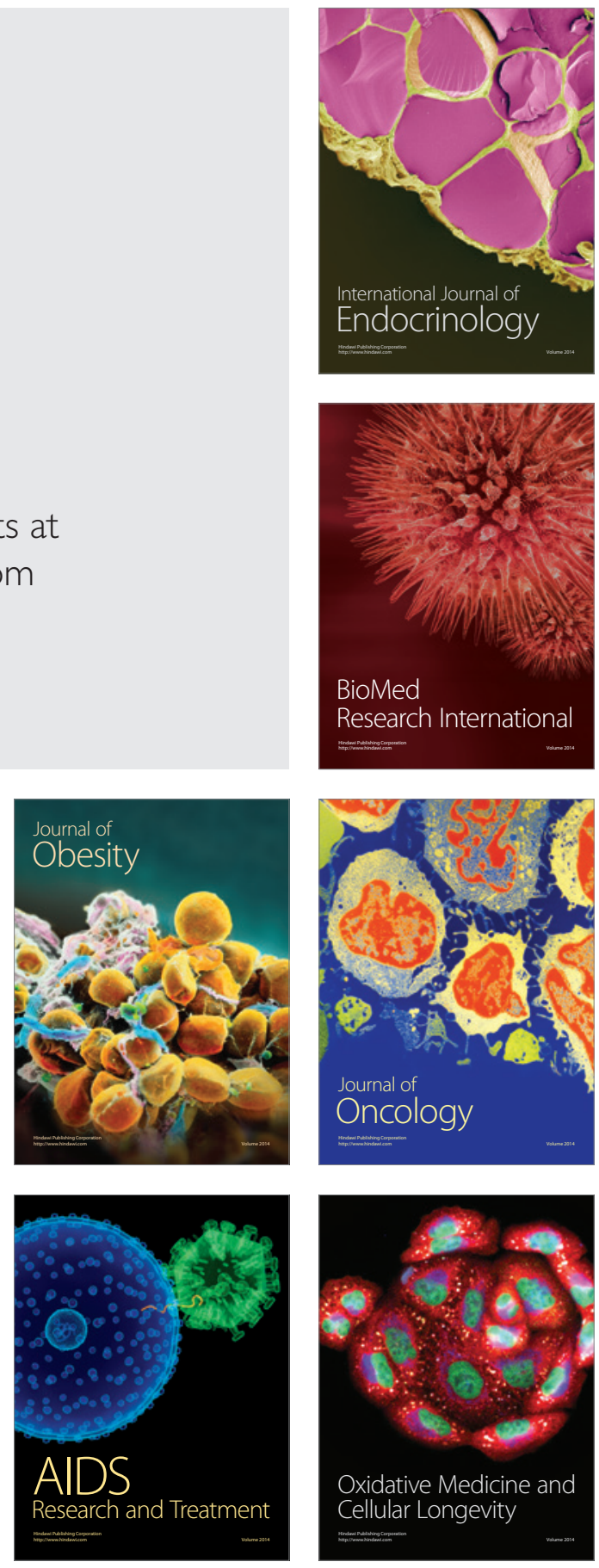